\title{
Operating Power System Under Reduced Generation Availability
}

\author{
Narinder K. Trehan, P.E., Senior Member IEEE \\ US Nuclear regulatory Commission
}

\begin{abstract}
Operating power system under reduced generation availability is a situation where the electricity generation capacity is inadequate to meet the load demand. The reduced generation could be the result of less available generating capacity, or inoperable capacity or unavailable capacity due to maintenance outages, or forced outages. The service of maintaining real time balance between generation and load is performed by Load Following that is one six specified Ancillary Services under Federal Energy Regulatory Commission's (FERC) 1996 Order No. 888. Without Load Following service, other service in particular Regulation does this function. Regulation is one of the other Ancillary Services that the transmission providers must provide. During the winter of 2000, and the summer of 2001, California that had not added a major power station even with an ever increasing demand for power due to an emerging digital technology had to operate the grid under reduced generation availability. Extreme drought conditions throughout the Pacific Northwest had also affected the available output of hydroelectric power resources to export to California. The reserve dropped below $1.5 \%$ (Stage 3) often and they declared a rolling blackout each time. During severe generation shortage situations, the electric utilities curtail interruptible loads to the extent required to maintain full Operating Reserves. If this does not stabilize the grid, then the licensees allow the operating reserve to go to zero but maintain the 10-minute reserve. If this also fails, the utilities implement a voltage reduction of $5 \%$ of normal operating voltage. An automatic under-frequency islanding scheme used on the west coast may also remove the burden on the transmission lines. If these actions are not enough, they implement brownouts and rotating blackouts to protect against a wide spread failure of the power system. Relaxation in environmental standards by the present administration has helped in the construction of the new power plants. In the mean time, advanced technologies such as FACTS, superconductivity, and SMES can provide support to the electric grid under reduced generation availability. The life extension program (license renewals) from 40 to 60 years for nuclear power plants and power uprates can also help to avoid operating the power system under reduced generation availability*.
\end{abstract}

Index Terms - License Renewal, load-shedding, operating reserves, power uprates, reduced generation, superconductivity.

\section{INTRODUCTION}

During the past decade, the demand for electricity in the United States has increased by 35 percent, whereas, the generation has increased only 18 percent. They require new additional generating capacity to meet the growth in electric power demand due to a booming economy in the United States. The net internal demand in North America in 2001 is 737.000 MW and the estimated generation is $889,000 \mathrm{MW}$ of which $55 \%$ is coal-fired, $22 \%$ is nuclear, $15 \%$ is gas fired, and $8 \%$ is hydro and oil fired. Operating power system under reduced generation availability is a situation where the electricity generation capacity is inadequate to meet the load demand. The reduced generation could be the result of less available generating capacity, or inoperable capacity or unavailable capacity due to maintenance outages, or forced outages. The service of maintaining real time balance between generation and load is performed by Load Following that is one of the six specified Ancillary Services under FERC's 1996 Order No. 888. Other five specified services that include backup supply, real power loss, dynamic scheduling, black start capability, and network stability. Without Load Following service, other services in particular Regulation performs this function. Regulation is one of the Ancillary Services that the transmission providers must provide.

Adjustments to real power (Watts) are made by throttle adjustments (governor settings) and adjustments to reactive power (reactive volt-ampere or VAR) are made by the generator field, voltage regulators and transformer taps. The excitation system that controls the reactive power flow by influencing the flux level is designed to give close voltage regulation under transient conditions. A generator tripping offline causes imbalance between generation and load, which can cause a decline in interconnected frequency and voltage. In response to frequency decline, the generators under governor control automatically increase output to begin to restore frequency to $60 \mathrm{Hertz}$. Generators under automatic generation control (AGC) increase output to restore the imbalance between generation and load within ten minutes.

\footnotetext{
*DISCLAIMER -- This paper represents the views of the author and does not represent a Nuclear Regulatory Commission (NRC) position on the subject covered in the paper. This paper is not a substitute for regulations, and compliance with it is not required. Methods and solutions different from those set out in the paper could be applied.
} 


\section{CRITERIA}

A reliable interconnected can survive disturbances, coincident with safe maximum power transfer in a static or dynamic situation during and following a contingency. Electric generating stations and transmission lines are sized to meet the customers' demand to meet operational and planning contingencies. To maintain reliability, the design criteria for generation capacity needed is based on probabilistic analyses aimed to meet a loss of load probability of one day in ten years.

\section{WHAT HAPPENS UNDER REDUCED GENERATION AVAILABILITY?}

Electric power systems that experience heavy loadings on the interconnected grid with limited VARs can be vulnerable to voltage instability. Such instability can cause tripping of the generators and transmission lines and may lead to a voltage collapse. Also, when the generation is reduced due to possible contingencies such as a loss of a generator, a loss of a transmission line or a failure of any other single component, the Operating Reserves (operating, spinning, and regulating) automatically provide the generation within 10 minutes. The power system is designed such that it is always ready to handle any single contingency. The spinning reactive reserve activated during a contingency should be replenished (recovered) so that the minimum reserves are maintained and the system is always ready for the next contingency.

Acceptable voltage levels across the interconnected system require a balance between the reactive power load demands and reactive power producing sources. Voltage instability may occur when the power system is unable to provide the required reactive power needed to meet the load demands. This may lead to uncontrolled separation, cascading outages, and consequently may lead to a voltage collapse. Voltage collapse is generally a slow process. During a system disturbance, the system voltage goes down due to VAR deficiency and the transformer taps mounted on the primary side of the transformer are raised to provide the VAR deficiency. As a result, the voltage on the low voltage side of the transformer is depressed which depresses the stator voltage. The stator voltage is restored by the automatic voltage regulator by increasing the generator excitation. Under reduced generation, the VARs produced by the generator are reduced and voltage instability occurs when the transmission system is inadequate to handle reactive power flows. The increased currents due to loss of VAR generation cause additional VAR flows and losses in the system and ultimately the voltage collapses. Complex systems with a large number of voltage sources and loads behave on the P-V characteristic. A more complex system analysis uses $\mathrm{P}-\mathrm{V}$ and V-Q characteristics. V-Q characteristic is used for the requirements of VAR compensation and gives better results because reactive power is related to voltage stability. Western System Coordinating Council widely use the V-Q curves. Dynamic voltage stability study should also include tap changing transformers, automatic governor control, generator maximum excitation limiters.

\section{ACTIONS TAKEN DURING REDUCED GENERATION AVAILABILITY}

In a situation where the available capacity resources are insufficient to meet the anticipated load demand (including the required Operating reserves), the operators may not have sufficient time to stabilize the electric system. Under such circumstances, automatic undervoltage load shedding and under-frequency load shedding may be used to provide reactive and real power support to deal with power deficiency. Following are different ways to operate the electric system under reduced power generation availability:

\section{A. Load Conservation Procedures}

During severe generation shortage situations, the electric utilities have Emergency Load Conservation Procedures in place that implements actions such as curtailing interruptible loads to the extent required to maintain full Operating Reserves. If these actions do not bring the stability of the electric grid, then the licensees allow the operating reserve to go to zero but maintain the 10-minute reserve.

1) Western Coast: The western grid uses long transmission lines and relatively few interconnections compared with the eastern grid. An automatic frequency load-shedding scheme is required to keep the generation and interconnected transmission system secured. If enough generation is not available, an automatic islanding scheme (islanding into four or five regions by under-frequency relay) may remove the burden on the transmission lines. If the individual system was importing power before the separation, the generation would be insufficient to match the demand and the frequency within that system would drop and under-frequency load shedding is an alternative to restore the frequency to most of the customers. On the other hand, if the individual system was exporting power before the separation, the frequency within the system would rise because the generated power would exceed the demand and tripping some generating units would restore the frequency. In the latter case, underfrequency load shedding does not take place. The utilities use customers' appeals as a corrective action to improve the dynamic security of power system. Further actions such as brownouts and rotating blackouts are implemented to protect against a wide spread failure of the power system. A voltage reduction commonly used on the east coast ( e.g., in New England) and the rest of the world was not used on the west coast. It has an effective application under the conditions of reactive power deficiency. A $5 \%$ voltage reduction essentially reduces customers' demand and allows a utility to 
stretch out its supply during times of excess demand. This is one step that allows utilities to maintain uninterrupted service to customers thus avoiding rotating blackouts. The overall savings in power for a 5 percent voltage reduction is about 2 percent. A 5 percent voltage reduction does not affect the house service as standard household appliances and electrical equipment are manufactured with $+/-10$ percent voltage tolerance. NEMA MG 1-20.45 states that low voltage motors shall operate successfully, under running conditions at rated load and frequency with a voltage not more than 10 percent above or below rated voltage. On June 27, 2001, California's three major utilities (Pacific Gas \& Electric, Southern California Edison and San Diego Gas \& Electric) agreed to reduce the voltage from the present level of 120 volts to roughly 117 volts. The utilities will turn down voltages at substations statewide. Such a step could save 500 megawatts of electricity in the state during hot days - enough electricity for 375,000 homes. There is a negligible effect on the efficiency of a motor running at a reduced voltage.

2) Eastern Coast: Independent System Operator (ISO) New England has procedures implemented if the demands for electricity go beyond operable limits. The steps taken include operating generators at the maximum levels, purchasing power from neighboring states, curtailing power as previously arranged with certain consumers, allowing the 30minute reserve to go to zero, implementing $5 \%$ voltage reductions to the extent to maintain 10-minute synchronized reserve and initiate radio and television appeals for voluntary load curtailment. During a severe shortage of generation, load shedding of a block of customers is implemented. Manual load shedding allows at least $50 \%$ of its load in 10 minutes and, therefore, should be used in extreme cases.

\section{B. Imports from Neighboring States}

Under reduced available generation, they can import the power supply from the neighboring power systems or they can buy power supply from independent power producers. During the winter of 2000 and summer of 2001, California that had not added a major power station even with an ever increasing demand for power due to a booming economy ran short of electricity. Higher emission costs, higher gas prices, more under-scheduling of loads and generation, unscheduled outages, unusual cold weather and reluctance of out-of-state generators' to deliver power fearing that the utilities could not pay them and affected the electric power supply. The state had to operate under reduced generation condition. After widespread outages that affected Western states in 1996, power flows along the Northwest-to-California Interties were decreased about $10 \%$ to provide a greater margin of stability. Extreme drought conditions throughout the Pacific Northwest had also affected the available output of hydroelectric power resources to export to California. The reserve dropped below $1.5 \%$ (Stage 3) six times from January to July 2001 and they declared a rolling blackout each time. California assembly passed legislation to fix the energy crisis by making the state a major electricity broker in buying and selling power.

\section{Energy Conservation}

The state governments continue to push conservation as a vital part of the rescue mission under reduced generation availability. After seeing the rotating blackouts in California, the residents reduced power consumption by 11 percent. The state is offering rebates to residents and businesses using energy efficient appliances and lighting. One such program offers a 20 percent rebate on utility bills if they cut power consumption by 20 percent.

\section{Reduced Generation Operating Reserves}

Generation operating reserves can be reduced to meet load demands by using smart electric power systems so that with the reduced generation, the VAR losses can be reduced. Flexible AC Transmission System (FACTS) was introduced to make sure that there is flexibility in energy system so that it can adjust to swings in supply and demand without getting instability. FACTS provides transient voltage support and system regulation to damp system oscillations, enhance system security, and allow increased power transfer capability. FACTS technology uses high speed electronic controllers, advanced control technology, fibre optics, and microcomputers to provide the correct transmission voltage, line impedance and the phase angle between them. Wide Area Monitoring Systems (WAMS) using globe positioning system (GPS) transmit signals of disturbances to the control centers throughout the interconnected system by using FACTs controllers to effectively damp out the oscillations so that they can effectively utilize the generation resources under reduced generation condition. Online decision making is needed in order for the information supplied by WAMS to be interpreted in real time so that the data can be relayed to the control devices in the interconnected network.

\section{E. Power Factor Improvement}

Low power factor is one of the causes that demands excessive reactive power from the power system. The performance of the stability index is influenced by the system power factor. When the load power factor is 0.8 and higher, the index performs very well. The employment of capacitors, synchronous generators, static VAR compensators, phase shifters, series compensation etc. will bring the power factor closer to unity and will help the system under reduced generation availability. Reactive power supply from generation sources is one of the several ways used to perform transmission system voltage control under reduced generation availability. 


\section{F. Dispersed Generation}

Under reduced generation availability, dispersed power generation (or distributed power) such as microturbines, solar cells, wind turbines, fuel cells, diesel generators can also provide power. IEEE Std. P1547/Draft is helping to smooth the way for these alternate sources. Distributed power (or dispersed power) is a modular electric generator near the point of use. It ensures electric power during system outages, rolling blackouts and allows customers to use DP during high-cost peak periods. Distributed power can range from less than a kilowatt to tens of MW in size. Synergies can be used which is a nuclear power plant and the operators build additionally gas-fired peaking capacity unit on its nuclear plant site.

\section{G. Bringing Old Units Back on Line}

The utilities are motivated to bring back the units on line that are presently out of service. Recently, the licensee for WNP Unit 1 is planning to reactivate the nuclear power plant. This will help in reducing the chances of operating the power system under reduced generation availability.

\section{H. System Black Start Capability}

Another service called System Black Start Capability can also provide generation under reduced generation conditions. Black start generating units can start automatically without an external electric power and start other generating units to provide contingency reserves. After offsite power has been lost, non-black start generating units can be returned to service. During a contingency, when there is a shortage of reactive power, gas turbine units should be automatically started to produce reactive power and pumped storage plants, if operating in the pumping mode should be tripped and put in generating mode to produce reactive power. In the pumping mode, pumped storage plants are used to provide an additional system load and in the generating mode, they supply reactive power during peak load demands. Gas turbine plants have higher running costs, but are used as peaking units with a fast start capability.

\section{Power Uprate}

The power uprate (ranging from $2.4 \%$ to $20 \%$ ) in nuclear power generating station is a cost-effective method to increase their MW ratings. Nuclear regulatory Commission has already approved the application for power uprates for a number of nuclear power plants such as San Onofre Units 1 and 2, Diablo Canyon Units 1 and 2 in California. By power uprates, the U.S. electric supply can be increased by 12,000 MW by nuclear power plants only. The nuclear steam supply system can support an increase in the thermal power (MWt). MWt can also be increased by changing the steam generators in the pressurized water reactors. The MWe output of the generator can also be increased by raising the hydrogen pressure (from 60 to $75 \mathrm{psig}$ ). A turbine generator is generally the limiting component. With the increase in MWe, under power uprate modifications, there is a decrease in the MVAR because of the fixed main generator MVA. Shunt capacitors can compensate for the decrease in MVAR.

\section{J. License Renewal}

Of the existing 103 nuclear power plants in the U.S., five units have received approval from the Nuclear Regulatory Commission (NRC) for another 20 years of operation increasing their life span from 40 to 60 years. Three units have formal application under review and 26 other units intend to renew their licenses. The nuclear power plants that otherwise will be closed because of their life expectancy of 40 years will supply power for another 20 years. This will help the grid security. They will maintain the plant-specific licensing basis during the renewal term.

\section{K. Superconductivity}

Superconductivity refers to the conduction of electricity with almost zero resistance. This helps in reducing the line losses and allows the system to operate under reduced generation availability. In 2001, Detroit Edison Co. installed high temperature superconducting (HTS) cables at Frisbie station that increased the power carrying capacity of cables by a factor of three. The superconductors will be cooled by liquid nitrogen and made of Bismuth, Strontium, Calcium, Copper, and Oxygen (BSSCO). They are developing the designs of either warm dielectric or cold dielectric. In the former design, only the main phase conductors are operated at low temperatures and in the latter case, the entire cable is operated at low temperatures. The latter type can carry about five times the current of conventional cables with two-thirds of the losses.

Superconducting Magnetic Energy storage (SMES) allows the storage of large amounts of electricity in a superconducting electromagnetic coil until required. Complemented with inverters, Distributed SMES (D-SMES) can inject both real and reactive power quickly into the system during a contingency. They installed the world's first commercial D-SMES at substations in Wisconsin in the U.S. The Texas grid is installing four (transportable) D-SMES units (two in 2001 and two in 2002). These technologies have great potential in solving the grid problems and difficulties operating the power system under reduced generation.

\section{CONCLUSION}

Operating power system under reduced generation availability is a situation where the electricity generation capacity is inadequate to meet the load demand. The reduced generation could be the result of less available generating capacity, or inoperable capacity or unavailable capacity due 
to maintenance outages, or forced outages. The service of maintaining real time balance between generation and load is performed by Load Following that is one of the six specified Ancillary Services under Federal Energy Regulatory Commission's (FERC) 1996 Order No. 888. Without Load Following service, other services in particular Regulation performs this function. During the winter of the year 2000, and the summer of 2001, California that had not added a major power station even with an ever increasing demand for power due to an emerging digital technology had to operate the grid under reduced generation availability. The reserve dropped below $1.5 \%$ (Stage 3) six times during January to July 2001 and they declared a rolling blackout each time. During severe generation shortage situations, the electric utilities curtail interruptible loads to the extent required to maintain full Operating Reserves. If this does not stabilize the grid, then the licensees allow the operating reserve to go to zero but maintain the 10-minute reserve. If this also fails, the utilities implement a voltage reduction of $5 \%$ of normal operating voltage. An automatic under-frequency islanding scheme used on the west coast may also remove the burden on the transmission lines. If these actions are not enough, brownouts and rotating blackouts are implemented to protect against a wide spread failure of the power system. Relaxation in environmental standards by the present administration has helped in the construction of the new power plants. In the mean time, advanced technologies such as FACTS, superconductivity, and SMES can provide support to the electric grid under reduced generation availability. The life extension program (license renewals) from 40 to 60 years for nuclear power plants and power uprates can also help to avoid operating the power system under reduced generation availability.

\section{REFERENCES}

[1] John W. Pope, Director-Bulk Power Operations, Southern Services Inc.,"Reliability in Transition," Transmission \& Distribution world, 1997.

[2] The interconnected Operations Services Task force, North American Electric Reliability Council, White Paper, "Draft of Proposed Standards for Interconnected Operation Services.” 1999.

[3] North American Electric Reliability Council, "Survey of the Voltage Collapse Phenomenon," Summary of the Interconnection Dynamics Task Force, August, 1991[2] P. Kundur, "Power System Stability and Control," McGraw-Hill, 1994.

[4] Western Systems Coordinating Council, Draft, Reliability Subcommittee Revisions of December 8, 2000. NERC/WSCC Planning Standards.

[5] Elizabeth A. Bretz, Senior Associate Editor, IEEE Spectrum, "PJM Interconnection: Model of a Smooth Operator," June 2000.

[6] "High Power Electronics and Flexible AC Transmission System," IEEE Power engineering Review, July 1988.

[7] William V. Hassenzahl, "Application of Superconductivity to Electric Power Systems," IEEE Power Engineering Review, May 2000, Vol. 20

[8] Abdel-Aty Edris,EPRI," " FACTS Technology Development: An Update," IEEE Power Engineering Review, March 2000.

[9] Mario Rabinowitz, "Power Systems of the Future,", IEEE Power Engineering Review, March 2000.

[10] Warren Buckles and William V. Hasenzahl, "Superconducting Magnetic Energy Storage," IEEE Power Engineering Review, May 2000.

[11] Earl Hazan, Contributing Feature Editor, "A Word of Caution," Transmission \& Distribution World, February 1997
[12] North American Reliability Council, May 2001, "2001 Summer Assessment," Reliability of the Bulk Electricity supply in North America, North American Electric Reliability Council

[13] Karl Stahlkopf, June 2001, "Technology Offers Solutions to the Current Power Crisis," IEEE Spectrum

[14] Western Systems Coordinating Council, "Disturbance Report for the Power Outage that Occurred on the Western Interconnection August 1996," Salt Lake City, Utah

[15] British Electricity International, " Modern Power Station Practice" Volume L system operation, March 1990

[16] U.S. Department of Energy's Energy Information Administration Website, "Status of the California Electricity Situation."

[17] Stability of Large Electric Power System - IEEE Press, Edited by R.T. Byerly and E.W. Kimbark

[18] New Challenge: Voltage Stability, by Harrison K. Clark, Power Technologies, Inc. Printed in the IEEE Power Engg. Review, April 1990

[19] NEMA Standard Publication No. MG1, "Motors and Generators" 1989, MG 1-20.45, "Variations From Rated Voltage and Rated Frequency."

\section{BIOGRAPHY}

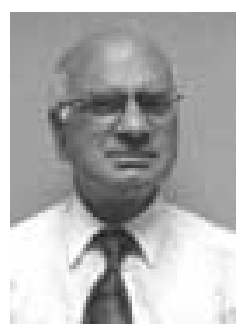

Narinder K. Trehan received B.Tech. (Honors) degree in Electrical Engineering from Indian Institute of Technology, Kharagpur, and an M.S. degree in Nuclear Engineering from the University of Maryland. From 1961 to 1979, he worked with different Architect Engineers such as Bechtel Power Corporation, and since 1979, he has been working with the U.S. Nuclear Regulatory Commission

He has published 14 technical papers on the subjects of degraded grid voltages, lighting design, impact of lightning strikes, electric utility deregulation, system stability, System security in an open market, failure of the uninterruptible power supplies, mis-coordination of protective devices, failure of dc systems associated with nuclear power generating stations. He chaired the Session on Nuclear power Systems (SNPS) in the 2000 IEEE Nuclear Science Symposium, Medical Imaging Conference and SNPS held on October 2000 in Lyon France. He is listed in the 2001 edition of International WHO'S WHO.

Chair of The U. S. President s Council of Year 2000 Conversion, thanked him by a letter for his contribution to minimize the effects of potential problems associated with the Year 2000 date change. He trained Russian and Ukrainian delegates regarding the licensing review of the electrical power systems of nuclear power generating stations. He was a previous member of the Working Group (W.G.) on IEEE Std. 387. He is currently a member of the W.G. 4.7 of IEEE Std. 741, member of the W.G. on IEEE Std. 944 and member of IEEE C37.105. The author participates in the weekly meetings (held on every Monday) with DOE, NERC, FERC and the National Laboratories on reliability of the US interconnected grid. He is Senior Member of IEEE and a registered Professional Engineer in the State of Maryland. 